\title{
A Study of Service Utilization and Client Satisfaction among Patients Attending a District Ayush Hospital in Karnataka
}

\author{
Anandaraj $\mathrm{R}^{1}$, Raghavendra $\mathrm{SK}^{2}$, Kavithai $\mathrm{P}^{3}$, Manu $\mathrm{AS}^{4}$ \\ ${ }^{I}$ Dept Of Community Medicine, Indira Gandhi Medical College \& Research Center, Pondicherry, India. \\ ${ }^{2}$ Dept Of Community Medicine, Adichunchanagiri Institute Of Medical Sciences, BG Nagara, Karnataka, India \\ ${ }^{3}$ Dept Of Community Medicine, Government Medical College, Thiruvananthapuram, Kerala, India \\ ${ }^{4}$ Dept Of Community Medicine, J.J.M. Medical College, Davangere, Karnataka, India
}

\begin{abstract}
:
Background : A multi provider health system comprising of modern as well traditional systems of medicine in the form of AYUSH is of paramount importance.

Objectives:

1. To study the utilization of services by patients attending District AYUSH Hospital, Davangere.

2. To find out the client satisfaction among patients towards AYUSH services offered.

Methodology: A cross sectional study was conducted among 335 patients attending in District AYUSH Hospital, Davangere in February - March 2014. Data was gathered by direct patient interviews as well as hospital records. Descriptive statistics was done using percentages and proportions.

Results: Among the services offered, ayurvedic treatment was mostly sought by the patients (45\%). Neurological ailments were the commonest reasons for seeking treatment in ayurveda (48\%), whereas it was musculoskeletal disorders in unani (20\%); gastrointestinal disorders in homeopathy (22\%) and non communicable diseases in yoga (30\%). Only $3 \%$ of the patients were cross referred from allopathic practitioners to AYUSH. Overall, $41.8 \%$ of the patients were satisfied and $50.7 \%$ were very much satisfied with the AYUSH services provided in the District AYUSH Hospital.

Conclusion: Majority of the patients were satisfied with the services offered by the District AYUSH hospital.

Keywords: AYUSH, Ayurveda, ISM\&H, Patient satisfaction, Service utilization
\end{abstract}

\section{Introduction}

Indian Systems of Medicine and Homoeopathy (ISM\&H) covers both the health systems which had originated in India and outside but got adopted and adapted in India in course of time. These include Ayurveda, Siddha, Unani, Yoga, Naturopathy and Homeopathy (AYUSH). These systems have been providing health care services to a large number of citizens, particularly in the rural areas. To promote ISM\&H, a Directorate of ISM and Homeopathy was set up in August, 1996, which evolved into Department of AYUSH in 2003 and subsequently into a separate Ministry of AYUSH in 2014.

As per National Family Health Services III reports, about $8 \%$ of under-five children in India were treated with herbal remedies. ${ }^{[1]}$ Despite many advantages such as fewer side effects, tried and tested methods of disease management and health promotion activities, the AYUSH sector has not been involved so far in public health interventions, for various reasons. Considering the size and distribution of Indian population, one can easily conclude that modern health system alone cannot provide health care services. ${ }^{[2]}$ To plan an effective strategy towards promoting AYUSH services, there is a dire need for information on the utilization of indigenous system of medicine by the community. Efforts made to assess the gaps and deficiencies in this system in relation to the various services provided are very minimal, and nil in this part of the nation. In addition to this, the needs of the beneficiaries have never been explored.

In this background, the present study was conducted to study the services utilization and client satisfaction among patients attending District AYUSH Hospital of Davangere in Karnataka.

\section{Materials And Methods}

A cross sectional study was conducted in February - March, 2014 among patients seeking treatment in District AYUSH Hospital (DAH) of Davangere district in Karnataka state located in South India. Informed consent was obtained from the patients before the start of the study. Using convenient sampling technique, about 335 patients were interviewed using a pre tested semi structured questionnaire to collect data regarding patient satisfaction. Data was also obtained from the records of the DAH from April 1st 2013 to March 31 st 2014 in order to study the service utilization pattern. Data entry and analysis was done using Microsoft Excel 2010. Percentages and proportions were calculated for descriptive statistics. 


\section{Results}

Totally 16,618 patients utilized the services of the District AYUSH Hospital in the year $2013-14$. Ayurveda (44.6\%) was the most commonly sought health system among the patients of DAH, followed by Unani (24.5\%), Yoga (20.2\%) and Homeopathy (10.7\%). Most of the pediatric patients availed Unani services $(41.7 \%)$ whereas adults preferred Ayurveda; both men (44.1\%) and women (50.0\%). [T ABLE: 1$]$

Symptoms related to neurology followed by gastroenterology were the commonly reported disorders by the patients. Almost $48 \%$ of those with neurological disorders followed ayurvedic medications. Unani was commonly sought for musculoskeletal disorders (20\%). About $30 \%$ of those suffering from non communicable diseases and $19 \%$ of those suffering from musculoskeletal disorders practiced Yoga. Homeopathy was largely followed by patients of gastrointestinal (22\%) and respiratory (17\%) illnesses. [Fig. 1]

About $64.2 \%$ of the patients had to wait for less than five minutes for consulting their doctors. The doctor spent about five to fifteen minutes in consultation for $62.6 \%$ of the patients and more than 15 minutes for $28.4 \%$ of the patients. About $53.7 \%$ opined that they need to wait for less than five minutes for receiving their medicines, while $46.3 \%$ collected them immediately. More than $95 \%$ of the patients were satisfied with the working timings of the hospital. Only $9 \%$ of the patients were not satisfied with the medications and care provided. Satisfaction level of patients about the behavior of doctors and staff present in the DAH was $95.5 \%$.

About $34.3 \%$ of the respondents opined that they were not satisfied with the privacy levels for female patients attending the DAH. Only 10 (3.0\%) patients were referred from allopathic practitioners to AYUSH, while the remaining sought the services either on their own $(44.8 \%)$ or referred by friend or relatives $(52.2 \%)$. Overall, $50.7 \%$ of the patients were very much satisfied with the services provided by the District AYUSH Hospital, while only $7.5 \%$ were not satisfied with the same. [TABLE: 2]

\section{Discussion}

Evaluation studies conducted in other parts of the country reveal similar results in many aspects as that of the present study. In Delhi, gastrointestinal disorders and arthritis were the most commonly sought complaints in Ayurvedic dispensaries. About $49.1 \%$ patients getting Ayurvedic treatment were attended by the doctor within 15 minutes of their waiting. ${ }^{[3]}$ In our study, more than $90 \%$ of the patients told that they spent for around fifteen minutes for their consultation with the doctors.

A nationwide study covering 35 districts in 19 states of India revealed that $32.3 \%$ of those who seek AYUSH services are suffering from common ailments while $17.9 \%$ sought for serious ailments. ${ }^{[4]}$ In a study done in Rajasthan, $58.3 \%$ reported that they faced discriminatory behavior by the doctors whereas it was only $4.5 \%$ in the present study. ${ }^{[5]}$

About $34 \%$ of the patients reported lack of privacy for examining female patients. This may reiterate the need for having national standards for infrastructure of AYUSH dispensaries and hospitals, though very few states do have one. Overall satisfaction level of patients in our study was above $90 \%$. This varied from $60 \%$ in Orissa $^{[6]}$ to $87 \%$ in Delhi. ${ }^{[3]}$ Rastogi et al observed that overall satisfaction level of patients availing pancha karma therapy was $94 \% .^{[7]}$

In our study, only $3 \%$ were cross referred from allopathy to AYUSH. Similar findings were observed in studies done in other parts of the nation. ${ }^{[3,5]}$ The National Policy on Indian Systems of Medicine and Homoeopathy 2002 envisages the integration of AYUSH Systems into the health care delivery system as well as the national health programs so as to ensure optimal use of available infrastructure and man power. Providing what is unique in each health system to the patients as a complementary therapy should not be withheld. Sensitization of allopathic doctors regarding AYUSH services, strengthening infrastructure and supply chain of AYUSH drugs would pave a long way in mainstreaming of AYUSH.

\section{Figures And Tables}

Table 1: Percentage distribution of patients utilizing services of DAH.

\begin{tabular}{|c|c|c|c|c|}
\hline \multirow{2}{*}{ Health system } & Adultmales & Adult females & Children & Total \\
\cline { 2 - 5 } & $\mathrm{n}(\%)$ & $\mathrm{n}(\%)$ & $\mathrm{n}(\%)$ & $\mathrm{n}(\%)$ \\
\hline Ayurveda & $3229(44.1)$ & $4112(50.0)$ & $75(6.9)$ & $7416(44.6)$ \\
\hline Unani & $2010(27.5)$ & $1602(19.5)$ & $452(41.7)$ & $4064(24.5)$ \\
\hline Yoga & $1346(18.4)$ & $1703(20.7)$ & $316(29.2)$ & $3365(20.2)$ \\
\hline Homeopathy & $732(10.0)$ & $801(9.7)$ & $240(22.2)$ & $1773(10.7)$ \\
\hline Total & $7317(100)$ & $8218(100)$ & $1083(100)$ & $16618(100)$ \\
\hline
\end{tabular}




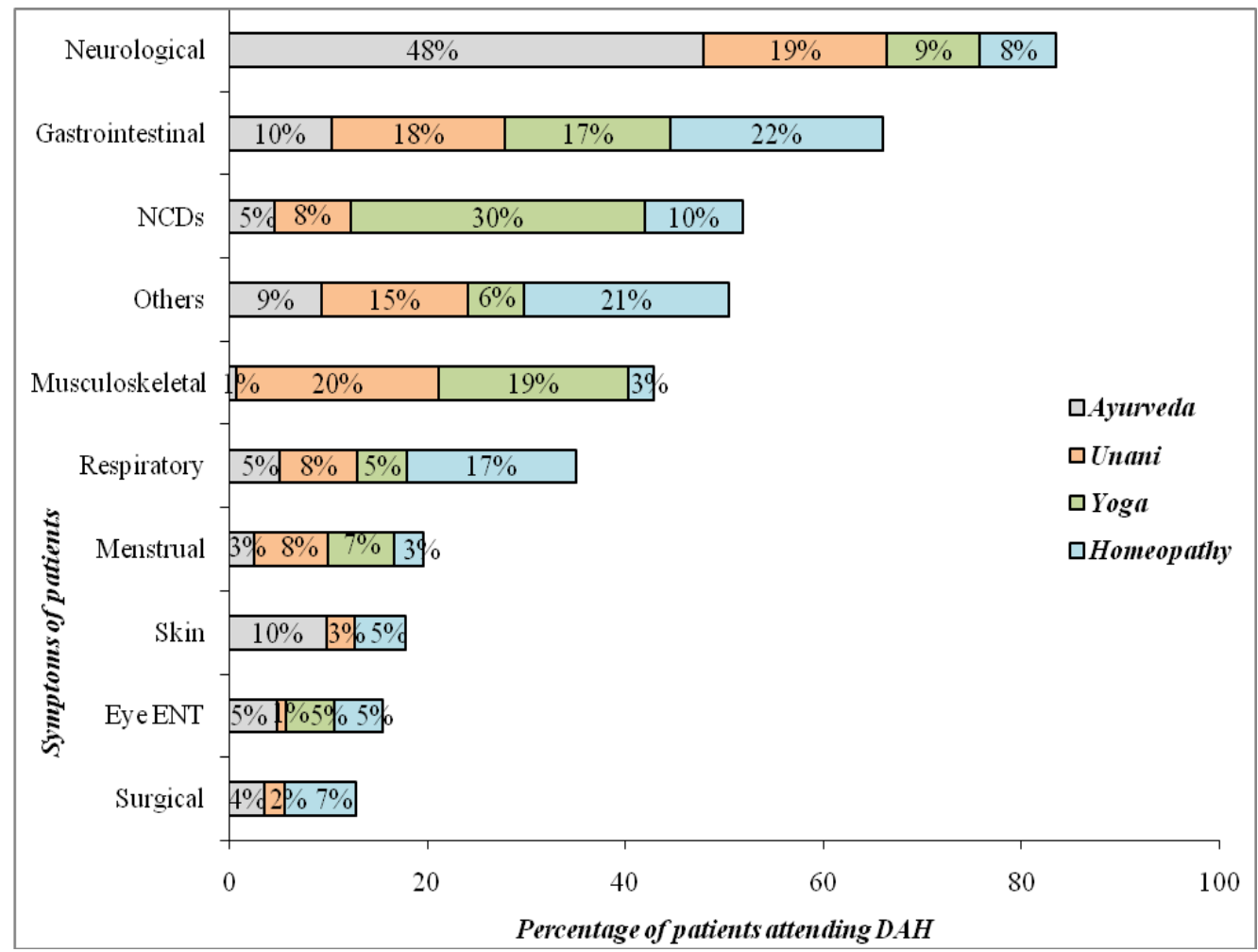

Figure 1: Symptom wise distribution of patients attending DAH.

Table 2: Factors relating to client satisfaction of patients attending DAH.

\begin{tabular}{|c|c|c|}
\hline Factors & Status & $\mathrm{n}(\%)$ \\
\hline \multirow{2}{*}{$\begin{array}{c}\text { Waiting time for } \\
\text { Doctor's consultation }\end{array}$} & Immediately & $120(35.8)$ \\
\hline & $<5$ minutes & $215(64.2)$ \\
\hline \multirow{3}{*}{ Doctor's consultation time } & $<5$ minutes & $30(9.0)$ \\
\hline & $5-15$ minutes & $210(62.6)$ \\
\hline & $>15$ minutes & $95(28.4)$ \\
\hline \multirow{2}{*}{$\begin{array}{l}\text { Waiting time for } \\
\text { receiving medicines }\end{array}$} & Immediately & $155(46.3)$ \\
\hline & $<5$ minutes & $180(53.7)$ \\
\hline \multirow{2}{*}{$\begin{array}{l}\text { Satisfaction with } \\
\text { working timings }\end{array}$} & Satisfied & $320(95.5)$ \\
\hline & Not satisfied & $15(4.5)$ \\
\hline \multirow{2}{*}{$\begin{array}{c}\text { Satisfaction with } \\
\text { medicines \& care provided }\end{array}$} & Satisfied & $305(91.0)$ \\
\hline & Not satisfied & $30(9.0)$ \\
\hline
\end{tabular}

\begin{tabular}{|c|c|c|}
\hline Factors & Status & $\mathrm{n}(\%)$ \\
\hline \multirow{2}{*}{$\begin{array}{c}\text { Satisfaction with } \\
\text { privacy for female patients }\end{array}$} & Satisfied & $220(65.7)$ \\
\hline & Not satisfied & $115(34.3)$ \\
\hline \multirow{2}{*}{$\begin{array}{c}\text { Satisfaction with } \\
\text { behavior of doctors \& staff }\end{array}$} & Satisfied & $320(95.5)$ \\
\hline & Not satisfied & $15(4.5)$ \\
\hline \multirow{3}{*}{ Source of referral to AYUSH } & Allopathic practitioners & $10(3.0)$ \\
\hline & Friends, relatives & $175(52.2)$ \\
\hline & Own decision & $150(44.8)$ \\
\hline \multirow{3}{*}{$\begin{array}{l}\text { Overall satisfaction level of clients } \\
\text { seeking AYUSH services in DAH }\end{array}$} & Very much satisfied & $170(50.7)$ \\
\hline & Satisfied & $140(41.8)$ \\
\hline & Not satisfied & $25(7.5)$ \\
\hline
\end{tabular}

\section{Conclusion}

A vast majority of the patients were satisfied with the services provided by the District AYUSH Hospital. Diseases of chronic duration were most commonly consulted.

\section{Acknowledgements}

The authors thank the doctors and staff of District AYUSH Hospital for their invaluable assistance in carrying the study. We also thank the patients without whom this work would have not been possible. 


\section{References}

[1]. National Family Health Survey (NFHS-III), 2005-06: India: Volume I. International Institute for Population Sciences (IIPS) and Macro International. Mumbai.

[2]. A study report on situational analysis, assessment of expressed need and standardization of "AYUSH" healthcare facilities in Chhattisgarh, 2010. State health resource centre \& Dept. of AYUSH, Chhattisgarh.

[3]. Evaluation study report on ayurvedic dispensaries of Delhi Government, 2006. Planning department. (Evaluation unit). Govt. of NCT of Delhi.

[4]. Singh P, Yadav RJ, Pandey A. Utilization of indigenous systems of medicine \& homoeopathy in India. Indian $J$ Med Res. 2005 Aug;122(2):137-42. PubMed PMID:16177471.

[5]. Assessment of AYUSH in Rajasthan after mainstreaming, 2010. Society for Economic Development \& Environmental Management.

[6]. Evaluation study of ayurvedic and homoeopathic dispensaries and herbal gardens in all the eight KBK districts of Orissa, 2006. Orissa Voluntary Health Association, Bhubhaneshwar.

[7]. Rastogi S. Effectiveness, safety, and standard of service delivery: A patient-based survey at a pancha karma therapy unit in a secondary care Ayurvedic hospital. J Ayurveda Integr Med. 2011 Oct;2(4):197-204. 